\title{
Молекулярно-цитогенетические нарушения в клетках слущенного эпителия у больных раком слизистой оболочки полости рта
}

\author{
Голуб Е.В., Шкаврова Т.Г., Полькин В.В., Михайлова Г.Ф., Цепенко В.В., \\ Севрюков Ф.Е., Медведев В.С., Исаев П.А.
}

\begin{abstract}
Медицинский радиологический научный центр имени А.Ф. Цыба - филиал Федерального государственного бюджетного учреждения «Научный медицинский исследовательский центр радиологии» Министерства здравоохранения Российской Федерации. 249036, Калужская область, Обнинск, ул. Королёва, д. 4
\end{abstract}

Актуальность. По современным представлениям, в патогенезе онкологических заболеваний ведущую роль играют молекулярно-генетические нарушения. Их встречаемость и клиническая значимость при раке слизистой оболочки полости рта (СОПР) недостаточно изучена.

Целью исследования было изучение в клетках слущенного эпителия СОПР молекулярно-цитогенетического профиля нарушений хромосом 7, 11 и генов EGFR, CCND1 у больных раком COПP.

Методы. Использован метод флуоресиентной іn situ гибридизации (FISH) с применением ДНК-зондов ген/иентромера хромосомы: EGFR/CEP7 и CCND1/CEP11. Исследование проводили на мазках с опухоли различной локализачии, взятых у 38 больных раком СОПР с различными стадиями заболевания до начала лечения. Контролем служили мазки СОПР 12 клинически здоровых лич.

Результаты. В клетках слущенного эпителия СОПР у здоровых лиц и больных раком наблюдаются клетки с нарушением копийности генов EGFR и/или CCND1 (потеря копии и амплификачия), моносомией хромосом 7 и/или 11, а также с их полисомией, представленной в основном трисомией и тетрасомией. У больных выявлены клетки с высокой степенью амплификации исследованных генов и клетки с полисомией, содержащие 5 и более чентромер, которые не встречались у здоровых лич. В группе больных среднегрупповые показатели нарушений статистически значимо ( $p<0,01)$ превышали контрольный уровень для частоты клеток с полисомией хромосомы $7(26,95 \%$ vs $0,67 \%)$ u хромосомы 11 (21,15\% vs 0,21\%), а также амплификации генов EGFR (6,45\% vs 0,13\%) u CCND1 (14,27\% vs 0,83\%). 4астота клеток с амплификачией генов EGFR и CCND1, а также полисомией хромосом 7 и 11 статистически значимо превышала контрольный уровень у 79\%, 79\%, 95\% и 90\% больных, соответственно.

Заключение. Установлено, что для больных раком СОПР клинически значимыми нарушениями, выявляемыми в клетках слущенного эпителия СОПР могут быть полисомия хромосом 7, 11 и амплификация генов EGFR, CCND1. Эти нарушения являются показателями нестабильности генома и, вероятно, могут служить не только независимыми прогностическими маркерами прогрессии опухоли, рецидива и метастазов, но также иметь потенциальную прогностическую значимость для оченки индивидуальной радиочувствительности, что позволит персонифицировать методы лечения больных раком СОПР.

Ключевые слова: рак слизистой оболочки полости pma; FISH; полисомия; EGFR; CCND1; амплификачия генов.

Для цитирования: Голуб Е.В., Шкаврова Т.Г., Полькин В.В., Михайлова Г.Ф., Цепенко В.В., Севрюков Ф.Е., Медведев В.С., Исаев П.А. Молекулярно-цитогенетические нарушения в клетках слущенного эпителия у больных раком слизистой оболочки полости рта. Патогенез. 2019; 17(4): 69-77

DOI: $10.25557 / 2310-0435.2019 .04 .69-77$

Для корреспонденции: Голуб Елена Викторовна, e-mail: mgp@mrrc.obninsk.ru Финансирование. Исследование не имеет спонсорской поддержки.

Конфликт интересов. Авторы заявляют об отсутствии конфликта интересов. Поступила: 30.07.2019

\section{Molecular cytogenetic abnormalities in exfoliated epithelial cells of patients with oral squamous cell carcinoma}

Goloub E.V., Shkavrova T.G., Polkin V.V., Mikhailova G.F., Tsepenko V.V., Sevryukov F.E., Medvedev V.S., Isaev P.A.

A.Tsyb Medical Radiological Research Center, Branch of the National Medical Research Radiological Center, Korolev Str. 4, Obninsk of the Kaluga Region 249036, Russian Federation

Background. According to recent conceptions molecular genetic abnormalities play a leading role in the pathogenesis of oncologic diseases. The reoccurrence and clinical significance of these abnormalities in oral squamous cell carcinoma (OSCC) are still unclear.

Aim. The aim of this study was to investigate abnormalities in the molecular cytogenetic profile of chromosomes 7, 11 and EGFR, CCND1 genes in exfoliated oral mucosa cells from OSCC patients.

Methods. The study used fluorescence in situ hybridization (FISH) with a DNA probe for EGFR/CEP7 and CCND1/CEP11. The study was conducted on tumor smears collected from 38 OSCC patients with different localizations and stages of the disease before treatment. Smears of exfoliated oral mucosa cells from 12 healthy individuals were used as the control.

Results. Cells from both healthy subjects and oral cancer patients showed deletions of gene EGFR and/or CCND1, their amplification, and monosomy and polysomy of chromosome 7 and/or 11 represented mainly by trisomy and tetrasomy. Cells with highgrade amplification of the studied genes and polysomic cells containing 5 or more centromeres were found in patients but not in 
control subjects. In the patient group, the average frequency of abnormalities was significantly higher $(p<0.01)$ than in control, including the frequencies of chromosome 7 (26.95\% vs. $0.67 \%)$ and chromosome 11 (21.15\% vs 0.21\%) polysomy. The same was true for gene EGFR (6.45\% vs. 0.13\%) and gene CCND1 (14.27\% vs. $0.83 \%)$ amplifications. The frequencies of cells with EGFR and CCND1 amplifications and chromosome 7 and 11 polysomy were significantly higher than in control for $79 \%, 79 \%, 95 \%$, and $90 \%$ patients, respectively.

Conclusion. The chromosome 7 and 11 polysomy and gene EGFR and CCND1 amplifications detected in exfoliated epithelial cells of oral mucosa may be clinically significant for patients with OSCC. These disorders are markers of genome instability and may serve as prognostic factors for tumor progression, recurrence, and metastases. Moreover, they may also be potentially predictive for individual radiosensitivity, which would help individualizing therapy for patients with OSCC.

Key words: oral squamous cell carcinoma (OSCC); fluorescence in situ hybridization (FISH); polysomy; EGFR; CCND1; gene amplification.

For citation: Goloub E.V., Shkavrova T.G., Polkin V.V., Mikhailova G.F., Tsepenko V.V., Sevryukov F.E., Medvedev V.S., Isaev P.A.

[Molecular cytogenetic abnormalities in exfoliated epithelial cells of patients with oral squamous cell carcinoma]. Patogenez [Pathogenesis]. 2019; 17(4): 69-77 (in Russian)

DOI: $10.25557 / 2310-0435.2019 .04 .69-77$

For correspondence: Goloub Elena Viktorovna, e-mail: mgp@mrrc.obninsk.ru

Funding. The study had no sponsorship.

Conflict of interest. The authors declare no conflict of interest. Received: 30.07.2019

\section{Введение}

Онкогенез слизистой оболочки полости рта (COПР) является результатом накопления генетических нарушений, которые вызывают постепенный переход от дисплазии слизистой к инвазивной карциноме. При воспалительных поражениях, доброкачественных и диспластических изменениях молекулярно-цитогенетические нарушения, выявляемые методом флуоресцентной in situ гибридизации (FISH), встречаются редко. В злокачественных новообразованиях они обнаруживаются с высокой частотой и представляют собой как структурные нарушения (транслокации, делеции, дицентрики), так и численные, представляющие собой изменения числа хромосом (анеусомия) и/или числа копий генов, в частности, EGFR, ERBB2, CCND1, $V E G F A$ и $M Y C$ [1]. В дальнейшем было показано, что в процессе перехода от дисплазии к карциноме СОПР наблюдается, в основном, увеличение числа клеток с нарушениями генов $E G F R$ и $C C N D 1$. Повышенная копийность онкогенов приводит к аномальной пролиферации клеток за счет игнорирования контрольных точек G-S и G-M при митозе, что предотвращает апоптоз и способствует выживаемости клеток с этими нарушениями [2]. Анеусомия при плоскоклеточном раке СОПР в основном представлена полисомией хромосом, которая свидетельствует о нестабильности генома и является ранним событием в процессе канцерогенеза, а также может приводить к прогрессии и/или рецидиву опухоли [3].

Заболеваемость населения России раком полости рта в 2017 году составила 9287 случаев [4]. Несмотря на терапевтические достижения последнего десятилетия, достаточно высоки случаи локального рецидива рака СОПР. Возможно, это связано с тем, что даже после резекции остаются предзлокачественные клетки, гистологическая оценка которых ненадежна. Со временем эти клетки могут приводить к развитию опухоли на прилежащем к первичной опухоли месте или могут сформировать вторичную опухоль в другом месте.
Отсутствие значимого улучшения прогноза и лечения плоскоклеточного рака слизистой ротовой полости требует поиска молекулярных маркеров как для идентификации пациентов с высоким риском метастазов и рецидива рака СОПР, так и выбора эффективного курса лечения. Как правило, изучение молекулярно-цитогенетических нарушений при раке СОПР проводят на парафиновых блоках биопсийного или операционного материала. Однако, выполнение FISH-исследования на клетках слущенного эпителия, по-нашему мнению, имеет некоторые преимущества: неинвазивный метод взятия биоматериала, а также получение более качественного цитогенетического препарата с отдельно лежащими клетками, что облегчает FISH-анализ.

Целью настоящего исследования являлось изучение в клетках слущенного эпителия СОПР молекулярно-цитогенетического профиля нарушений хромосом 7,11 и генов $E G F R, C C N D 1$ у больных раком СОПР.

\section{Материалы и методы исследования}

В исследование включены 38 больных раком СОПР с различной его локализацией и стадиями заболевания, проходившие обследование и лечение в МРНЦ им. А.Ф. Цыба - филиал ФГБУ «НМИЦ радиологии» Минздрава России в период 2015-2018 гг. Исследование проводили на мазках с опухоли, взятых до начала лечения. Из них у 10 больных в качестве «внутреннего контроля» исследовали образцы СОПР, взятые с противоположной от опухоли стороны. Контролем служили мазки слизистой оболочки полости рта 12 клинически здоровых человек. Предметные стекла с нанесенными на них мазками помещали в фиксатор (смесь метанола и уксусной кислоты в соотношении 3:1). В настоящей работе, выполненной методом интерфазной флуоресцентной in situ гибридизации (FISH), были использованы коммерческие ДНК-зонды ген/ центромера хромосомы: $E G F R / \mathrm{CEP} 7$ и $C C N D 1 / \mathrm{CEP} 11$ (Kreatech, Нидерланды). Все пред- и постгибридиза- 
ционные отмывки, а также нанесение ДНК-зондов выполняли в соответствии с инструкциями фирмы производителя. Денатурация ДНК осуществлялась в автоматической камере Hybrite при $74^{\circ} \mathrm{C}$ в течение 7 минут. Гибридизация проходила при $37^{\circ} \mathrm{C}$ в термостате в течение 18 часов. После постгибридизационных отмывок для визуализации препаратов наносили DAPI (4,6-диамидино-2-фенилиндол). Анализ молекулярно-цитогенетических нарушений выполнялся на флуоресцентном микроскопе AxioImager (Zeiss). В каждом случае анализировали по 100-400 клеток. Клетки оценивали по категориям: нормальные (2 гена и 2 центромеры), с потерей одной копии гена, с амплификацией гена (рис. 1, А, 1, Б), с моносомией и полисомией хромосом (рис. 1, В).

Статистическую обработку данных проводили с помощью стандартных методов статистического анализа с использованием компьютерной программы Microsoft Excel (2007). При представлении полученных данных использованы следующие показатели описа- тельной статистики, характеризующие вариационный ряд: среднее выборки, стандартная ошибка среднего, максимальные и минимальные значения. Оценку достоверности различий проводили с использованием параметрических и непараметрических критериев ( $\mathrm{t}$-критерий $(\mathrm{t} \geqslant 1,96)$, U-критерий Манна-Уитни), в зависимости от результатов проверки выборок на нормальность распределения.

\section{Результаты исследования}

Результаты исследования молекулярно-цитогенетических нарушений в клетках слущенного эпителия в группах клинически здоровых лиц и больных раком слизистой оболочки полости рта представлены в табл. 1. Как видно из таблицы, в группе контроля наблюдались клетки с нарушением копийности генов $E G F R$ и/или CCND1 (потеря копии и амплификация), моносомией хромосом 7 и/или 11, а также с их полисомией, представленной трисомией и тетрасомией. Среднегруп-

Частота клеток с нарушением генов $E G F R, C C N D 1$ и анеусомией хромосом 7 и 11 в обследованных группах

Таблица 1

\begin{tabular}{|c|c|c|c|c|c|c|}
\hline \multirow{2}{*}{$\begin{array}{c}\text { Ген/ } \\
\text { центро- } \\
\text { мера }\end{array}$} & \multirow{2}{*}{ Группа } & \multirow{2}{*}{$N_{\mathrm{K}}$} & \multicolumn{4}{|c|}{ Среднегрупповая частота клеток с нарушением, \% } \\
\hline & & & Потеря гена & Амплификация гена & Моносомия & Полисомия \\
\hline \multirow{3}{*}{$\begin{array}{l}\text { EGFR/ } \\
\text { CEP7 }\end{array}$} & Контроль & 2400 & $0,21 \pm 0,09$ & $0,13 \pm 0,07$ & $0,17 \pm 0,08$ & $0,67 \pm 0,17$ \\
\hline & «Внутренний контроль» & 1900 & $0,37 \pm 0,14$ & $0,53 \pm 0,17^{*}$ & $0,47 \pm 0,16$ & $1,63 \pm 0,29 *$ \\
\hline & Больные & 6917 & $0,22 \pm 0,06$ & $6,45 \pm 0,30^{*}$ & $0,80 \pm 0,11^{*}$ & $26,95 \pm 0,53^{*}$ \\
\hline \multirow{3}{*}{$\begin{array}{l}\text { CCND1/ } \\
\text { CEP11 }\end{array}$} & Контроль & 2400 & $1,25 \pm 0,23$ & $0,83 \pm 0,19$ & $0,38 \pm 0,12$ & $0,21 \pm 0,09$ \\
\hline & «Внутренний контроль» & 1900 & $1,68 \pm 0,30$ & $1,00 \pm 0,23$ & $0,47 \pm 0,16$ & $0,21 \pm 0,11$ \\
\hline & Больные & 6166 & $0,62 \pm 0,10$ & $14,27 \pm 0,45^{*}$ & $0,68 \pm 0,10$ & $21,15 \pm 0,52^{*}$ \\
\hline
\end{tabular}

Примечания: $N_{\mathrm{K}}$ - количество проанализированных клеток, ${ }^{*}$ - статистически значимое превышение контрольного уровня ( $p<0,05$ по t-критерию).

A

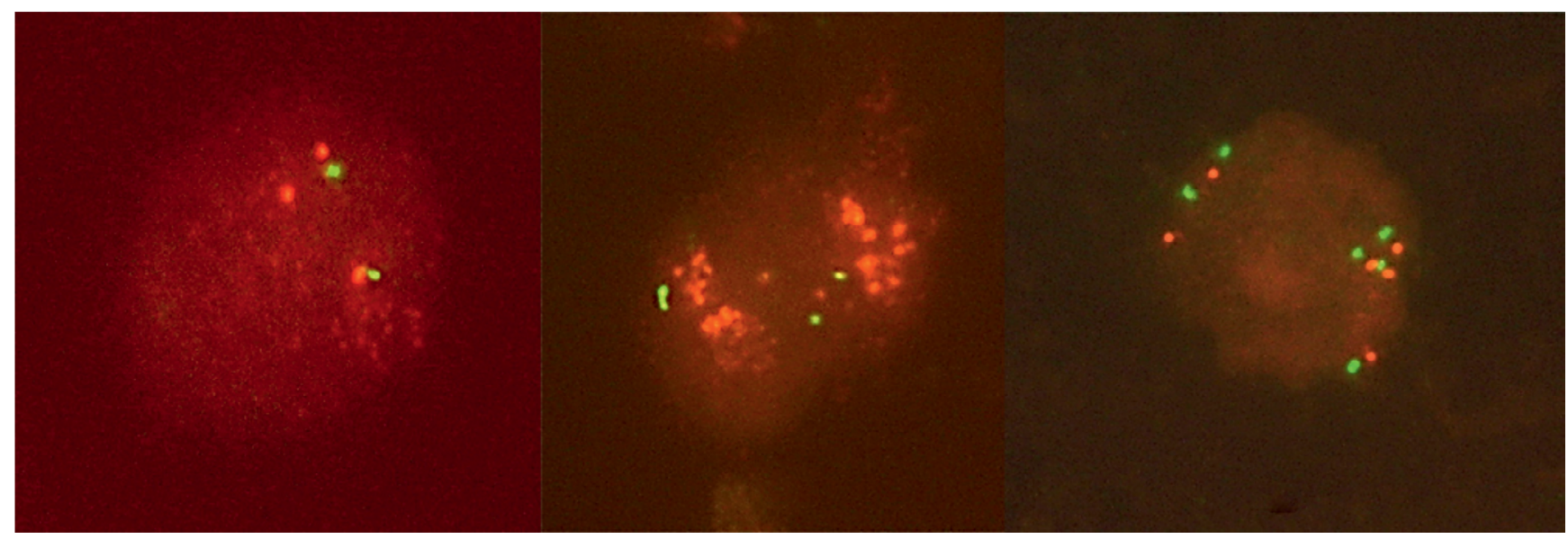

Рис. 1. Молекулярно-цитогенетические нарушения в клетках слущенного эпителия у больных раком слизистой оболочки полости рта: красный сигнал - ген EGFR, зелёный сигнал - центромера хромосомы 7. А - низкая степень амплификации гена EGFR (3 красных и 2 зелёных сигнала); Б - высокая степень амплификации гена EGFR (более 10 красных и 3 зелёных сигнала); В - полисомия хромосомы 7 (6 красных и 6 зелёных сигналов). 
повые частоты клеток с нарушениями не превышали $1,25 \%$.

В группе «внутреннего контроля» наблюдались аналогичные нарушения. Среднегрупповые частоты обнаружения клеток с нарушением копийности генов и анеусомией хромосом не превышали 1,68\% и достоверно не отличались от аналогичных показателей группы контроля. Статистически значимое превышение среднегрупповых показателей контрольной группы обнаружено только для амплификации гена $E G F R$ в 4,1 раза $(p<0,05)$ и полисомии хромосомы 7 в 2,4 раза $(p<0,01)$.

В группе больных наблюдался весь спектр нарушений, но в отличие от групп контроля и «внутреннего контроля», встречались клетки с высокой степенью амплификации исследованных генов (рис. 1, Б), а также клетки с полисомией, содержащие 5 и более исследованных хромосом (рис. 1, В). Частота клеток с амплификацией генов $E G F R$ и $C C N D 1$ колебалась в широком диапазоне: $0-22 \%$ и $0-87 \%$ соответственно. Их среднегрупповые значения статистически значимо $(p<0,01)$ превышали среднегрупповые значения контрольной группы: для гена $E G F R$ в 49,6 раз, для гена CCND1 в 17,2 раза.

Частота клеток с полисомией хромосом 7 и 11 также колебалась в очень широком диапазоне $2,5-98 \%$ и 0 - 70\% соответственно. Их среднегрупповые значения статистически значимо $(p<0,01)$ превышали среднегрупповые значения контрольной группы: для полисомии хромосомы 7 в 40,2 раза, для полисомии хромосомы 11 в 100,7 раз.

Таким образом, для больных раком СОПР клинически значимыми нарушениями, обнаруженными в клетках слущенного эпителия, могут быть полисомия хромосом 7 и 11, а также амплификация генов $E G F R$ и $C C N D 1$. Несмотря на то, что у больных среднегрупповая частота обнаружения клеток с моносомией хромосомы 7 достоверно выше, чем в контрольной группе, из-за невысоких индивидуальных частот обнаружения клеток с этим нарушением, их клиническая значимость маловероятна.

На рис. 2 представлены индивидуальные значения частоты обнаружения клеток с амплификацией генов $E G F R$ и CCND1 у больных раком COПР и лиц группы контроля.

Анализ представленных данных показал, что частота обнаружения клеток с амплификацией гена $E G F R$ достоверно превышала контрольный уровень у $79 \%$ (30 из 38) больных, у такого же числа больных наблюдалось достоверное превышение контрольного уровня по частоте обнаружения клеток с амплификацией гена $C C N D 1$, причем у подавляющего большинства (24 человека) наблюдалась амплификация обоих исследованных генов. Клетки с высокой степенью амплификации гена $E G F R$, которые не встречались в контроле, выявлены у 5 больных, а гена $C C N D 1-$ у 14 человек. Их частота обнаружения колебалась в интервале $2,5-10,0 \%$ и 1,3 - 72,0\% соответственно. Клетки с высокой степенью амплификации обоих генов обнаружены у трех человек.

На рис. 3 представлены индивидуальные значения частоты обнаружения клеток с полисомией хромосом 7 и 11 у больных раком СОПР и лиц группы контроля. Анализ данных показал, что частота обнаружения клеток с полисомией хромосомы 7 достоверно превышала контрольный уровень у 95\% (36 из 38) больных, а с по-

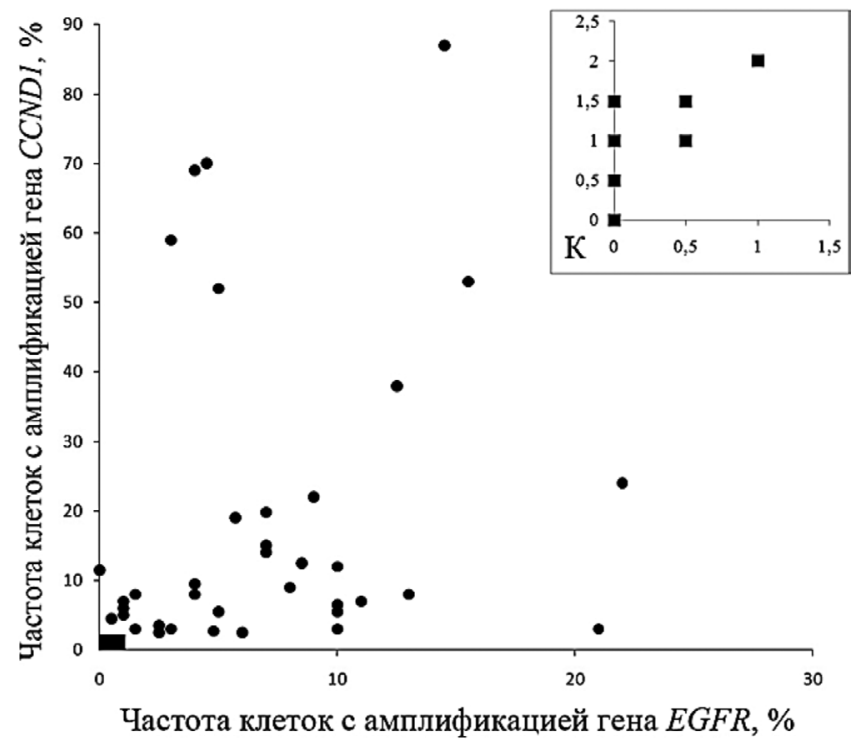

Рис. 2. Индивидуальные значения частоты обнаружения клеток с амплификацией генов EGFR и CCND1 у больных раком COПР (•) и группы контроля (•). В правом верхнем углу рисунка в увеличенном масштабе показаны данные лиц контрольной группы (K).

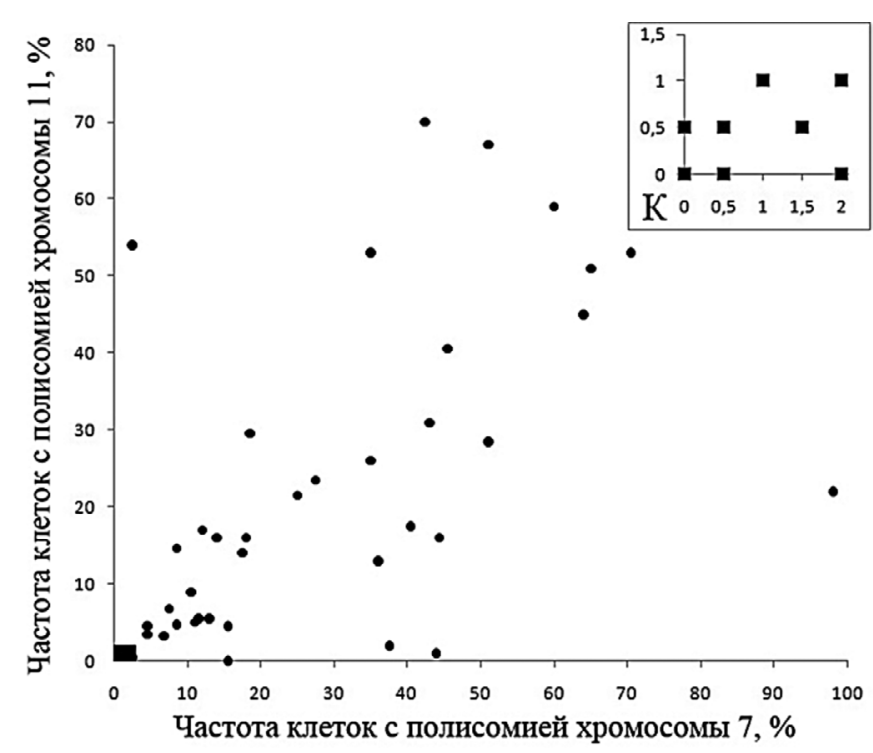

Рис. 3. Индивидуальные значения частоты обнаружения клеток с полисомией хромосом 7 и 11 у больных раком СОПР (•) и группы контроля (匹). В правом верхнем углу рисунка в увеличенном масштабе показаны данные лиц контрольной группы (K). 
лисомией хромосомы 11 - у 90\% (34 из 38) больных, и у 33 больных наблюдалась полисомия обеих хромосом. Полисомия была представлена в основном три- и тетрасомией хромосом. У 11 больных преобладали клетки с трисомией, а у $22-$ с тетрасомией хромосомы 7. Доля этих клеток от общего числа клеток с полисомией хромосомы 7 варьировала в диапазонах $42-100 \%$ и $43-89 \%$, соответственно.

Анализ частоты обнаружения клеток с полисомией хромосомы 11 показал, что клетки с трисомией преобладали у 16 больных, а с тетрасомией - у 17 больных. Доля этих клеток от общего числа клеток с полисомией хромосомы 11 варьировала в диапазонах $57-100 \%$, и $40-100 \%$, соответственно. Клетки с полисомией, содержащие 5 и более СЕР7 и/или СЕР11, которые не встречались в контроле, обнаружены у 29 больных и их частота обнаружения колебалась в интервале от $0,5 \%$ до $46,0 \%$.

Таким образом, из представленных выше результатов видно, что у больных раком СОПР наблюдается широкая индивидуальная вариабельность частоты обнаружения клеток как с амплификацией исследованных генов, так и полисомией хромосмом 7 и/или 11.

В табл. 2 представлены диапазоны колебания частоты обнаружения клеток с нарушениями у больных с различными стадиями заболевания. Как видно из таблицы, даже у больных, имеющих одинаковую стадию, наблюдался широкий диапазон колебаний исследованных показателей. Проведенный сравнительный анализ с использованием U-критерия Манна-Уитни не выявил статистически значимых различий $(p>0,05)$ частоты обнаружения клеток с нарушениями между группами больных с различными стадиями заболевания.

\section{Обсуждение}

Результаты молекулярно-цитогенетического анализа показали наличие у больных раком слизистой оболочки полости рта клеток с множественными нарушениями числа копий генов $E G F R, C C N D 1$, и анеусомией хромосом 7 и 11. В нашем исследовании клетки с потерей копии гена $E G F R$ и/или $C C N D 1$ встречались с низкой частотой - не более $3,0 \%$, а клетки с моносомией хромосом 7 и/или 11 - не более 5,0\%. Авторы [5] тоже отметили, что ни в одном из исследованных ими образцов опухоли не обнаружены клетки с потерей копии генов $E G F R$ и $C C N D 1$. Вероятно, эти молекулярно-генетические нарушения не являются характерными для рака СОПР и, как правило, исследователями не принимаются во внимание.

Увеличение числа копий исследованных генов, в отличие от их потери, в клетках у больных раком СОПР является частым событием. Амплификация генов $E G F R$ и $C C N D 1$ наблюдалась в образцах рака слизистой оболочки ротовой полости на ранней стадии заболевания, а также при инвазии и метастазах в лимфоузлы, свидетельствуя о важном и независимом значении амплификации в процессе патогенеза $[1,6,7]$. По результатам проведенного нами исследования частота клеток с амплификацией генов $E G F R$ и $C C N D 1$ у больных до начала лечения максимально составляла $22 \%$ и $87 \%$ соответственно, и значимо превышала контрольный уровень у $79 \%$ больных $(p<0,05)$. Следует отметить, что среднегрупповая частота обнаружения клеток с амплификацией гена $C C N D 1$ была в 2,2 раза выше, чем с амплификацией гена $E G F R(14,3 \%$ vs $6,5 \%)$. В работе [5] авторы после проведения многофакторного анализа при использовании модели пропорциональных рисков (регрессия Кокса) выявили корреляцию клеток с амплификацией гена CCND1 с безрецидивной выживаемостью $(p<0,001)$. Статистически значимое ухудшение безрецидивной $(p=0,048)$ и общей выживаемости $(p=0,001)$ пациентов связывают с увеличением числа копий генов $E G F R$ и $C C N D 1$ и другие авторы [8].

Присутствие клеток с амплификацией гена $E G F R$ может быть показателем агрессивности опухоли и свидетельствует о высокой предрасположенности к метастазам и пролиферации в рецидивирующую опухоль [9, 10]. Это подтверждают авторы [6], показав, что вероятность развития метастазов у пациентов с амплификацией гена $E G F R$ в первичной опухоли составляет $68,4 \%$ (McNemar test: $p=0,389)$, а рецидива - 65,9\% (McNemar test: $p=0,510)$. Развитие метастазов в лимфатических узлах наблюдали также у больных, имеющих опухолевые клетки с повышенным числом копий гена CCND1 при

Таблица 2

Частота обнаружения клеток с нарушениями у больных раком СОПР с различными стадиями заболевания

\begin{tabular}{|c|c|c|c|c|c|}
\hline \multirow{3}{*}{$\begin{array}{c}\text { Стадия заболе- } \\
\text { вания }\end{array}$} & \multirow{3}{*}{$\begin{array}{l}\text { Число больных } \\
\quad(\mathrm{n}=38)\end{array}$} & \multicolumn{4}{|c|}{ Диапазон колебания частоты клеток с нарушениями, \% } \\
\hline & & \multicolumn{2}{|c|}{ Амплификация гена } & \multicolumn{2}{|c|}{ Полисомия } \\
\hline & & $E G F R$ & $C C N D 1$ & Хромосома 7 & Хромосома 11 \\
\hline 1 & 2 & $3,0-14,5$ & $3,0-87,0$ & $15,5-43,0$ & $0-36,0$ \\
\hline 2 & 11 & $0-21,0$ & $0-59,0$ & $4,5-64,0$ & $2,0-70,0$ \\
\hline 3 & 14 & $0-13,0$ & $2,5-52,0$ & $4,5-65,0$ & $0,5-59,0$ \\
\hline 4 & 11 & $1,0-22,0$ & $3,5-70,0$ & $2,5-98,0$ & $9,0-67,0$ \\
\hline
\end{tabular}


немелкоклеточном раке легких ( $p=0,043)$ [11], а гена $E G F R$ - в значительной части вульварных карцином [12]. В нашем исследовании у 24 больных обнаружена амплификация обоих генов. В работе [13] при раке молочной железы анализ прогностической значимости амплификации и коамплификации исследованных генов, в том числе $E G F R$ и $C C N D 1$, выявил ухудшение выживаемости больных с увеличением числа амплифицированных генов на опухолевую клетку $(p<0,001)$.

По современным представлениям амплификация гена $E G F R$ является одним из показателей к таргетной терапии. Положительный ответ на EGFR-специфичные ингибиторы тирозинкиназы обнаружен при исследованиях in vitro и in vivo у пациентов с амплификацией гена $E G F R$ при раке СОПР [7, 14]. Эффективность применения ингибиторов $E G F R$ в качестве терапевтической альтернативы подтверждена и для больных группы вульварных карцином [12]. С другой стороны, при наличии клеток с амплификацией обоих генов, EGFR и CCND1, может не наблюдаться положительного эффекта таргетной терапии. Как известно, повышенная копийность гена CCND1 сопровождается гиперэкспрессией белка циклин D1, который является одним из компонентов сигнальных путей активации $E G F R$, задействованных в популяции неопластических клеток, и, как предполагают авторы [15], может приводить к резистентности опухоли к EGFR-ингибиторам. Поэтому необходима одновременная оценка обоих генов не только с прогностической целью, но и терапевтической. Важно учитывать, что повышенная копийность гена $E G F R$ может быть результатом полисомии хромосомы 7. В таком случае, как считают авторы [7], увеличение числа копий гена $E G F R$ является маркером только риска развития рака слизистой оболочки полости рта, а не чувствительности к $E G F R$-специфичным ингибиторам тирозинкиназы.

Амплификация генов $E G F R$ и CCND1 является одним из важнейших механизмов процесса канцерогенеза и наблюдается практически при всех стадиях заболевания. Авторы работ [6, 16] выявили взаимосвязь амплификации этих генов не только с метастазами в лимфоузлы и глубиной инвазии, но и со стадией опухоли СОПР. При этом в других исследованиях такой зависимости не обнаружили $[1,17]$. Полученные нами результаты на небольшой группе больных также не показали статистически значимой зависимости частоты обнаружения клеток с амплификацией генов $E G F R$ и CCND1 от стадии заболевания.

Другим значимым молекулярно-цитогенетическим нарушением является полисомия хромосом 7 и 11, которая в основном была представлена клетками с три- и тетрасомией СЕР7 и СЕР11. У одних больных преобладали клетки с трисомией, и максимальная частота их по отношению к общему числу клеток с полисомией достигала одинаково 100\% для СЕР7 и СЕР11. У других больных, наоборот, с большей частотой встречались клетки с тетрасомией СЕР7 и СЕР11 - до 89\% и 100\% от общего числа клеток с полисомией соответствую- щих хромосом 7 и 11. Как показано в работе [18], полисомия свидетельствует о нестабильности генома, что ведет не только к прогрессии опухоли, но и позволяет оценить общий и 5-летний уровень безрецидивной выживаемости. Авторы [5] обнаружили корреляцию клеток с трисомией CEP7/EGFR с общей выживаемостью $(p=0,001)$ больных, а при наличии одновременно еще и клеток с амплификации гена $C C N D 1$ больные попадают в группу плохого прогноза. Авторы другого исследования [19] также считают, что полисомия хромосом может служить прогностическим фактором в оценке выживаемости, поскольку 5-летний уровень безрецидивной выживаемости был ниже при наличии полисомии, чем при ее отсутствии $(47,1 \%$ vs $88,9 \%$, $p=0,012)$. Поскольку в нашем исследовании практически у всех обследованных больных выявлены клетки с полисомией СЕР7 и СЕР11, то можно предположить, что не только сам факт обнаружения таких клеток, но и количество клеток с нарушениями, найденными у больного, имеет клиническое значение.

Хромосомная нестабильность, оцененная по количеству копий хромосом 1 и 7 в резекционных образцах первичной опухоли, также значимо ассоциировала с локорегиональными рецидивами $(p=0,008)$, выявленными в 9 из 11 случаев через 5 лет после резекции опухоли [13]. Очевидно, что при полисомии, кроме повышения копийности исследованных генов, увеличивается число копий и других генов, расположенных на хромосоме, которые в комплексе содействуют более агрессивному поведению опухоли. Вероятно, это дает опухоли дополнительные селективные преимущества для прогрессирования, способности к метастазированию, экспрессии факторов роста.

Особого внимания заслуживает результат анализа 10 образцов «внутреннего контроля» больных раком СОПР. Источник клеток с нарушениями копийности генов и полисомией хромосом пока неясен. Это могут быть слущенные клетки с первичной опухоли или клетки с молекулярно-цитогенетическими нарушениями, которые присутствуют в условно чистом месте слизистой оболочки полости рта, откуда брали мазок для «внутреннего контроля». Тем не менее, полученное нами статистически значимое $(p<0,05)$ превышение обнаружения частоты клеток с амплификацией гена $E G F R$ и полисомией хромосомы 7 в образцах «внутреннего» контроля по сравнению с аналогичными показателями в контроле может свидетельствовать о процессе активации в них сигнальных путей $E G F R$, которые приводят к повышению пролиферации малигнизированных клеток [10]. Эти клетки могут служить потенциальным источником рецидивов и/или вторичных опухолей.

\section{Заключение}

В настоящее время всё большую актуальность для диагностики и лечения онкологических заболеваний 
приобретает применение биологических маркёров. Молекулярно-генетические маркёры и их сочетание позволяют диагностировать онкозаболевание, провести дифференциальную диагностику, определить прогноз течения заболевания, подобрать оптимальную тактику лечения [8, 12, 16, 20].

Изучение молекулярно-цитогенетического профиля нарушений хромосом 7, 11 и генов $E G F R, C C N D 1$ в клетках слущенного эпителия показало, что у здоровых лиц и больных раком СОПР наблюдаются клетки с нарушением копийности генов EGFR и/или CCND1, моносомией хромосом 7 и/или 11, а также с их полисомией, представленной трисомией и тетрасомией. У больных наблюдались клетки с высокой степенью амплификации исследованных генов и клетки с полисомией, содержащие 5 и более центромер, которые не встречались у здоровых лиц. Установлено, что для больных раком СОПР клинически значимыми нарушениями, выявляемыми в клетках слущенного эпителия, могут быть полисомия хромосом 7 и 11, а также амплификация генов $E G F R$ и $C C N D 1$. Эти нарушения являются показателями нестабильности генома и, вероятно, могут служить не только независимыми прогностическими маркерами прогрессии опухоли, рецидива и метастазов, но также иметь потенциальную прогностическую значимость для оценки индивидуальной радиочувствительности, что позволит персонифицировать методы лечения больных раком СОПР.

\section{Список литературы}

1. Martín-Ezquerra G., Salgado R., Toll A., Gilaberte M., Baró T., Alameda Quitllet F., Yébenes M., Solé F., Garcia-Muret M., Espinet B., Pujol R.M. Multiple genetic copy number alterations in oral squamous cell carcinoma: study of MYC, TP53, CCDN1, EGFR and ERBB2 status in primary and metastatic tumours. Br. J. Dermatol. 2010; 163(5): 1028-1035. DOI: 10.1111/j.1365-2133.2010.09947.x

2. Tsantoulis P.K., Kastrinakis N.G., Tourvas A.D., Laskaris G., Gorgoulis V.G. Advances in the biology of oral cancer. Oral Oncol. 2007; 43(6): 523-534. DOI: 10.1016/j.oraloncology.2006.11.010

3. Bockmühl U., Petersen I. DNA ploidy and chromosomal alterations in head and neck squamous cell carcinoma. Virchows Arch. 2002; 441(6): 541-550. DOI: 10.1007/s00428-002-0729-3

4. Каприн А.Д., Старинский В.В., Петрова Г.В. Злокачественные новообразования в России в 2017 году (заболеваемость и смертность). М.: МНИОИ им. П.А. Герцена - филиал ФГБУ «НМИЦ радиологии» Минздрава России, 2018. http://www.oncology.ru/ service/statistics/malignant_tumors/2017.pdf (дата обращения: 30.08.2019).

5. Takahashi K.I., Uzawa N., Myo K., Okada N., Amagasa T. Simultaneous assessment of cyclin D1 and epidermal growth factor receptor gene copy number for prognostic factor in oral squamous cell carcinoma. Oral Sci. Int. 2009; 6(1): 8-20. DOI: 10.1016/S13488643(09)80009-8

6. Huang S.F, Chien H.T., Cheng S.D., Chuang W.Y., Liao C.T., Wang H.M. EGFR copy number alterations in primary tumors, metastatic lymph nodes, and recurrent and multiple primary tumors in oral cavity squamous cell carcinoma. BMC Cancer. 2017; 17: 592-600. DOI: 10.1186/s12885-017-3586-9

7. Benchekroun M. T., Saintigny P., Thomas S. M., El-Naggar A. K., Papadimitrakopoulou V., Ren H., Lang W., Fan Y. H., Huang J., Feng L., Lee J. J., Kim E. S., Hong W. K., Johnson F. M., Grandis J. R., Mao L. Epidermal growth factor receptor expression and gene copy number in the risk of oral cancer. Cancer Pre.v Res. (Phila). 2010; 3(7): 800-809. DOI: 10.1158/1940-6207.CAPR-09-0163

8. Nakata Y., Uzawa N., Takahashi K. I., Sumino J., Michikawa C.,
Sato H., Sonoda I., Ohyama Y., Okada N., Amagasa T. EGFR gene copy number alteration is a better prognostic indicator than protein overexpression in oral tongue squamous cell carcinomas. Eur. J. Cancer. 2011; 47(15): 2364-2372. DOI: 10.1016/j.ejca.2011.07.006

9. Alshami M.L., Majeed A.H. Fluorescent in situ hybridization evaluation of epidermal growth factor receptor and cyclin D1 genes in oral squamous cell carcinoma. J. Pioneer Med. Sci. 2016; 6(1): 1-5.

10. Chiang W.F., Liu S.Y., Yen C.Y., Lin C.N., Chen Y.C., Lin S.C., Chang K.W. Association of epidermal growth factor receptor (EGFR) gene copy number amplification with neck lymph node metastasis in areca-associated oral carcinomas. Oral Oncology. 2008; 44(3): 270276. DOI: $10.1016 /$ j.oraloncology.2007.02.008

11. Riessmann P.T, Koga H., Figlin R.A., Holmes E.C., Slamon D.J. Amplification and overexperssion of cyclin D1 and epidermal growth factor receptor gene in non-small-cell lung cancer. Lung cancer study group. J. Cancer Res. Clinoncol. 1999; 125(2): 61-70. DOI: 10.1007/ s004320050243

12. Woelber L., Hess S., Bohlken H., Tennstedt P., Eulenburg C., Simon R., Gieseking F., Jaenicke F., Mahner S., Choschzick M. EGFR gene copy number increase in vulvar carcinomas is linked with poor clinical outcome. J. Clin. Pathol. 2012; 65(2): 133-139. DOI: 10.1136/jcp-2010-079806

13. Al-Kuraya K., Schraml P., Torhorst J., Tapia C., Zaharieva B., Novotny H., Spichtin H., Maurer R., Mirlacher M., Köchli O., Zuber M., Dieterich H., Mross F., Wilber K.,Simon R., Sauter G. Prognostic relevance of gene amplifications and coamplifications in breast cancer. Cancer Res. 2004; 64(23): 8534-8540. DOI: 10.1158/0008-5472.CAN-04-1945

14. Petty R.D., Dahle-Smith A., Stevenson D.A.J., Osborne A., Massie D., Clark C., Murray G.I., Dutton S.J., Roberts C., Chong I.Y., Mansoor W., Thompson J., Harrison M., Chatterjee A., Falk S.J., Elyan S., Garcia-Alonso A., Fyfe D.W., Wadsley J., Chau I., Ferry D.R., Miedzybrodzka Z. Gefitinib and EGFR Gene Copy Number Aberrations in Esophageal Cancer. J. Clin. Oncol. 2017; 35(20): 2279-2287. DOI: $10.1200 /$ JCO.2016.70.3934

15. Uzawa N., Sonoda I., Myo K., Takahashi K., Miyamoto R., Amagasa T. Fluorescence in situ hybridization for detecting Genomic Alterations of Cyclin D1 and p16 in oral squamous cell carcinoma. Cancer. 2007; 110(10): 2230-2239. DOI: 10.1002/cncr.23030

16. Wangsa D., Chowdhury S.A., Ryott M., Gertz E.M., Elmberger G., Auer G., Åvall Lundqvist E., Küffer S., Ströbel P., Schäffer A.A., Schwartz R., Munck-Wikland E., Ried T., Heselmeyer-Haddad K. Phylogenetic analysis of multiple FISH markers in oral tongue squamous cell carcinoma suggests that a diverse distribution of copy number changes is associated with poor prognosis. Int. J. Cancer. 2016; 138(1): 98-109. DOI: 10.1002/ijc.29691

17. Bernardes V.F., Gleber-Netto F.O., Sousa S.F., Rocha R.M., Aguiar M.C. EGFR status in oral squamous cell carcinoma: comparing immunohistochemistry, FISH and CISH detection in a case series study. BMJ Open. 2013; 3(1). DOI: 10.1136/bmjopen-2012-002077

18. Siebers T.J., Bergshoeff V.E., Otte-Höller I., Kremer B., Speel E.J., van der Laak J.A., Merkx W.M., Slootweg P.J. Chromosome instability predicts the progression of premalignant oral lesions. Oral Oncol. 2013; 49(12): 1121-1128. DOI: 10.1016/j.oraloncology.2013.09.006

19. Pierssens D.D.C.G., Borgemeester M.C., van der Heijden S.J.H., Peutz-Kootstra C.J., Ruland A.M., Haesevoets A.M., Kessler P.A.W.H., Kremer B., Speel E.M. Chromosome instability in tumor resection margins of primary OSCC is a predictor of local recurrence. Oral Oncol. 2017; 66: 14-21. DOI: 10.1016/j.oraloncology.2016.12.029

20. Пронина И.В., Логинов В.И., Ходырев Д.С., Казубская Т.П., Брага Э.А. Профили изменения экспрессии генов GPX1, RHOA и NKIRAS1 как потенциальные диагностические маркеры немелкоклеточного рака легкого. Патогенез. 2018; 16(3): 116-120. DOI: $10.25557 / 2310-0435.2018 .03 .116-120$

\section{References}

1. Martín-Ezquerra G., Salgado R., Toll A., Gilaberte M., Baró T., Alameda Quitllet F., Yébenes M., Solé F., Garcia-Muret M., Espinet B., Pujol R.M. Multiple genetic copy number alterations in oral squamous cell carcinoma: study of MYC, TP53, CCDN1, EGFR and ERBB2 status in primary and metastatic tumours. Br. J. Dermatol. 2010; 163(5): 1028-1035. DOI: 10.1111/j.1365-2133.2010.09947.x

2. Tsantoulis P.K., Kastrinakis N.G., Tourvas A.D., Laskaris G., Gorgoulis V.G. Advances in the biology of oral cancer. Oral Oncol. 2007; 43(6): 523-534. DOI: 10.1016/j.oraloncology.2006.11.010 
3. Bockmühl U., Petersen I. DNA ploidy and chromosomal alterations in head and neck squamous cell carcinoma. Virchows Arch. 2002; 441(6): 541-550. DOI: 10.1007/s00428-002-0729-3

4. Kaprin A.D., Starinsky V.V., Petrova G.V. [Malignant neoplasms in Russia in 2017 (morbidity and mortality)]. M.: MNIOI im. P.A. Gertcena - filial FGBU «NMIC radiologii» Minzdrava Rossii, 2018. http://www.oncology.ru/service/statistics/malignant_tumors/2017. pdf (Retrieved 30.08.2019) (in Russian)

5. Takahashi K.I., Uzawa N., Myo K., Okada N., Amagasa T. Simultaneous assessment of cyclin D1 and epidermal growth factor receptor gene copy number for prognostic factor in oral squamous cell carcinoma. Oral Sci. Int. 2009; 6(1): 8-20. DOI: 10.1016/S13488643(09)80009-8

6. Huang S.F, Chien H.T., Cheng S.D., Chuang W.Y., Liao C.T., Wang H.M. EGFR copy number alterations in primary tumors, metastatic lymph nodes, and recurrent and multiple primary tumors in oral cavity squamous cell carcinoma. BMC Cancer. 2017; 17: 592-600. DOI: 10.1186/s12885-017-3586-9

7. Benchekroun M. T., Saintigny P., Thomas S. M., El-Naggar A. K., Papadimitrakopoulou V., Ren H., Lang W., Fan Y. H., Huang J., Feng L., Lee J. J., Kim E. S., Hong W. K., Johnson F. M., Grandis J. R., Mao L. Epidermal growth factor receptor expression and gene copy number in the risk of oral cancer. Cancer Pre.v Res. (Phila). 2010; 3(7): 800-809. DOI: 10.1158/1940-6207.CAPR-09-0163

8. Nakata Y., Uzawa N., Takahashi K. I., Sumino J., Michikawa C., Sato H., Sonoda I., Ohyama Y., Okada N., Amagasa T. EGFR gene copy number alteration is a better prognostic indicator than protein overexpression in oral tongue squamous cell carcinomas. Eur. J. Cancer. 2011; 47(15): 2364-2372. DOI: 10.1016/j.ejca.2011.07.006

9. Alshami M.L., Majeed A.H. Fluorescent in situ hybridization evaluation of epidermal growth factor receptor and cyclin D1 genes in oral squamous cell carcinoma. J. Pioneer Med. Sci. 2016; 6(1): 1-5.

10. Chiang W.F., Liu S.Y., Yen C.Y., Lin C.N., Chen Y.C., Lin S.C., Chang K.W. Association of epidermal growth factor receptor $(E G F R)$ gene copy number amplification with neck lymph node metastasis in areca-associated oral carcinomas. Oral Oncology. 2008; 44(3): 270276. DOI: 10.1016/j.oraloncology.2007.02.008

11. Riessmann P.T, Koga H., Figlin R.A., Holmes E.C., Slamon D.J. Amplification and overexperssion of cyclin D1 and epidermal growth factor receptor gene in non-small-cell lung cancer. Lung cancer study group. J. Cancer Res. Clinoncol. 1999; 125(2): 61-70. DOI: 10.1007/ s004320050243

12. Woelber L., Hess S., Bohlken H., Tennstedt P., Eulenburg C., Simon R., Gieseking F., Jaenicke F., Mahner S., Choschzick M. EGFR gene copy number increase in vulvar carcinomas is linked with poor clinical outcome. J. Clin. Pathol. 2012; 65(2): 133-139. DOI: 10.1136/ jcp-2010-079806

13. Al-Kuraya K., Schraml P., Torhorst J., Tapia C., Zaharieva B., Novotny H., Spichtin H., Maurer R., Mirlacher M., Köchli O., Zuber M., Dieterich H., Mross F., Wilber K.,Simon R., Sauter G. Prognostic relevance of gene amplifications and coamplifications in breast cancer. Cancer Res. 2004; 64(23): 8534-8540. DOI: 10.1158/0008-5472.CAN-04-1945

14. Petty R.D., Dahle-Smith A., Stevenson D.A.J., Osborne A., Massie D., Clark C., Murray G.I., Dutton S.J., Roberts C., Chong I.Y., Mansoor W., Thompson J., Harrison M., Chatterjee A., Falk S.J., Elyan S., Garcia-Alonso A., Fyfe D.W., Wadsley J., Chau I., Ferry D.R., Miedzybrodzka Z. Gefitinib and EGFR Gene Copy Number Aberrations in Esophageal Cancer. J. Clin. Oncol. 2017; 35(20): 2279 2287. DOI: $10.1200 / J C O .2016 .70 .3934$

15. Uzawa N., Sonoda I., Myo K., Takahashi K., Miyamoto R., Amagasa T. Fluorescence in situ hybridization for detecting Genomic Alterations of Cyclin D1 and p16 in oral squamous cell carcinoma. Cancer. 2007; 110(10): 2230-2239. DOI: 10.1002/cncr.23030

16. Wangsa D., Chowdhury S.A., Ryott M., Gertz E.M., Elmberger G., Auer G., Åvall Lundqvist E., Küffer S., Ströbel P., Schäffer A.A., Schwartz R., Munck-Wikland E., Ried T., Heselmeyer-Haddad K. Phylogenetic analysis of multiple FISH markers in oral tongue squamous cell carcinoma suggests that a diverse distribution of copy number changes is associated with poor prognosis. Int. J. Cancer. 2016; 138(1): 98-109. DOI: 10.1002/ijc.29691

17. Bernardes V.F., Gleber-Netto F.O., Sousa S.F., Rocha R.M., Aguiar M.C. EGFR status in oral squamous cell carcinoma: comparing immunohistochemistry, FISH and CISH detection in a case series study. BMJ Open. 2013; 3(1). DOI: 10.1136/bmjopen-2012-002077

18. Siebers T.J., Bergshoeff V.E., Otte-Höller I., Kremer B., Speel E.J., van der Laak J.A., Merkx W.M., Slootweg P.J. Chromosome instability predicts the progression of premalignant oral lesions. Oral Oncol. 2013; 49(12): 1121-1128. DOI: 10.1016/j.oraloncology.2013.09.006

19. Pierssens D.D.C.G., Borgemeester M.C., van der Heijden S.J.H., Peutz-Kootstra C.J., Ruland A.M., Haesevoets A.M., Kessler P.A.W.H., Kremer B., Speel E.M. Chromosome instability in tumor resection margins of primary OSCC is a predictor of local recurrence. Oral Oncol. 2017; 66: 14-21. DOI: 10.1016/j.oraloncology.2016.12.029

20. Pronina I.V., Loginov V.I., Khodyrev D.S., Kazubskaya T.P., Braga E.A. Changes in GPX1, RHOA and NKIRAS1 gene expression profiles as potential diagnostic markers for non-small cell lung cancer]. Patogenez. [Pathogenesis]. 2018; 16(3): 116-120 DOI: 10.25557/23100435.2018.03.116-120 (in Russian)

\section{Сведения об авторах:}

Голуб Елена Викторовна - доктор биологических наук, ведущий научный сотрудник лаборатории молекулярно-генетической патологии Медицинского радиологического научного центра имени А.Ф. Цыба филиала Федерального государственного бюджетного учреждения «Научный медицинский исследовательский центр радиологии» Министерства здравоохранения Российской Федерации; https://orcid.org/00000002-6424-064X

Шкаврова Татьяна Геннадьевна - кандидат биологических наук, старший научный сотрудник лаборатории молекулярно-генетической патологии Медицинского радиологического научного центра имени А.Ф. Цыба - филиала Федерального государственного бюджетного учреждения «Научный медицинский исследовательский центр радиологии» Министерства здравоохранения Российской Федерации; https:// orcid.org/0000-0002-7950-2585

Полькин Вячеслав Викторович - кандидат медицинских наук, заведующий отделением лучевого и хирургического лечения заболеваний верхних дыхательных путей Медицинского радиологического научного центра имени А.Ф. Цыба - филиала Федерального государственного бюджетного учреждения «Научный медицинский исследовательский центр радиологии» Министерства здравоохранения Российской Федерации; https://orcid.org/0000-0003-0857-321X

Михайлова Галина Федоровна - доктор биологических наук, заведующая лабораторией молекулярно-генетической патологии Медицинского радиологического научного центра имени А.Ф. Цыба - филиала Федерального государственного бюджетного учреждения «Научный медицинский исследовательский центр радиологии» Министерства здравоохранения Российской Федерации; https://orcid.org/0000-0003-4158-0147 
Цепенко Виктория Викторовна - кандидат биологических наук, старший научный сотрудник лаборатории молекулярно-генетической патологии Медицинского радиологического научного центра имени А.Ф. Цыба - филиала Федерального государственного бюджетного учреждения «Научный медицинский исследовательский центр радиологии» Министерства здравоохранения Российской Федерации; https:// orcid.org/0000-0002-5278-0809

Севрюков Феликс Евгеньевич - доктор медицинских наук, заведующий отделом лучевого и хирургического лечения заболеваний головы и шеи Медицинского радиологического научного центра имени А.Ф. Цыба - филиала Федерального государственного бюджетного учреждения «Научный медицинский исследовательский центр радиологии» Министерства здравоохранения Российской Федерации; https:// orcid.org/0000-0002-9756-6275

Медведев Виктор Степанович - доктор медицинских наук, заведующий отделением радиохирургического лечения закрытыми радионуклидами Медицинского радиологического научного центра имени А.Ф. Цыба - филиала Федерального государственного бюджетного учреждения «Научный медицинский исследовательский центр радиологии» Министерства здравоохранения Российской Федерации

Исаев Павел Анатольевич - доктор медицинских наук, ведущий научный сотрудник отделения радиохирургического лечения закрытыми радионуклидами Медицинского радиологического научного центра имени А.Ф. Цыба - филиала Федерального государственного бюджетного учреждения «Научный медицинский исследовательский центр радиологии» Министерства здравоохранения Российской Федерации; https://orcid.org/0000-0001-9831-4814 